Type of the Paper (Case Report)

\title{
Assessment and control of termites infestation in the Holy Monastery of Saint Catherine, Sinai, Egypt
}

\author{
Sabrina Palanti ${ }^{1, *}$ and Georgios Tavlaridis ${ }^{2}$ \\ 1 CNR IBE Institute of Bioeconomy; sabrina.palanti@ibe.cnr.it \\ 2 Saint Catherine Holy Monastery at Mount Sinai, Egypt; jorgostavlaridis@yahoo.it \\ * Correspondence: sabrina.palanti@ibe.cnr.it;
}

\begin{abstract}
Simple Summary: This paper describes a survey of a termite infestation of holy Monastery of Saint Catherine and the attempt to block it with an European bait system. Authors, consider this research experiment, funded by Dow AgroSciences,, Italy, and not published before, remarkable of publication in form of case report. At the time, the Project Leader Dr Georgios Tavlaridis of project funded by ENI IEOC (International Egyptian Oil company), for the conservation Main Church of the holy Monastery of Saint Catherine, Sinai Egypt, asked to Laboratory of Biodegradation and Preservation of Italian National Research Council, CNR IRL, now CNR IBE, in chief of Dr Sabrina Palanti, , of carrying out, in collaboration with Dow AgroSciences Italy, a research for the eradication of termites infestation without to use toxic and unhealthy chemical substances. So started a collaboration between CNR and Dow AgroSciences Italy for testing the bait system, commercialized in Italy at the time, for applying it to other termite species found in the Monastery. It was decided in accordance with the archbishop of Monastery that gave us all the necessary assistance for carrying out the project.
\end{abstract}

\begin{abstract}
The research is based on the inspection performed in June 2002 for carrying out a research program for the eradication of a termite infestation due a desertic species in the area of the Saint Catherine Holy Monastery at Mount Sinai - Egypt. The paper describes the application of the registered European bait system Sentritech ${ }^{\mathrm{TM}}$ and the trend of eradication during the first year. The application of bait system blocked the termite infestation inside the Katholikon (Main church) and in the surrounding after 6 months. Nevertheless, the infestation restarted and even increased again in the surrounding of the main church. An explanation of this surprising event is attempted in this paper.
\end{abstract}

Keywords: Higher Termites; Coco nucifera; Fagus sylvatica, Pinus nigra subs laricio; Sentritech ${ }^{\mathrm{TM}}$; hexaflumuron.

\section{Introduction}

The Greek Orthodox Monastery of Saint Catherine was constructed from architect Stephanus of Aila in $6^{\text {th }}$ century in the South of Sinai Peninsula in Egypt, during the command of the Emperor Justinian, and it is the oldest continuously inhabited Christian Monastery, with a history that can be traced back over seventeen centuries. The Monastery stands at the foot, $1580 \mathrm{~m}$ above sea level, of Mount Horeb, where, in accordance with the Old Testament, Moses received the Tablets of the Law. The mountain is known and revered by Muslims as Jebel Musa. The entire area is sacred to three most important of the world religions: Christianity, Islam, and Judaism and is the oldest Christian Monastery still in use for its initial function. Its walls (Justinian Fortress) and the Katholikon (Main church), constructed in the $6^{\text {th }}$ century are of great significance to studies of Byzantine architecture and the Monastery houses outstanding collections of early Christian manuscripts, icons, 
the Transfiguration mosaic and the original wooden functional trusses of the roof. The rugged mountainous landscape, containing numerous archaeological and religious sites and monuments, forms a perfect backdrop to the Monastery that was nominated as World Heritage Site of UNESCO by World Heritage Committee in 2002 [1].

The paper describes the in situ inspection and the measures adopted to control and to eliminate a termite infestation reported by authors in Holy Monastery of St Catherine, Sinai in 2002.

Previously, in 2001 one of the authors carried out a preliminary inspection in the places where monks individuated termite tunnels and decay. In fact, they reported that in May 2001, there was the swarming of winged termites, and to control it they applied a preservative treatment a based on copper and zinc, CUPRINOL (Permetrin 0.1\%; Acetipetac Zinc 14.3\%), AkzoNobel, UK.

The aim of the inspection was based on the eradication the termite infestation with an eco-friendly method, used in Europe and well documented at the time [2]. The method based on baits, after the laboratory and in field research steps, [3], [4], [5], become commercially available in 1995 in USA market (SENTRI ${ }^{\mathrm{TM}}$ ). The baits utilized in this experiment contained $0.5 \%(\mathrm{w} / \mathrm{w})$ of Hexaflumuron and another insecticide, a benzoylurea, that is an Insect Growth Regulator (IGR). Hexaflumuron blocks the synthesis of chitin, that is the main constituent of exoskeleton of termites and prevents insects moulting. Further the transferring of active principles between the colony is assured by workers through trophallaxis.

\section{Materials and Methods}

The investigation and the eradication of termites was performed with the bait system by Dow Agroscience registered in Europe as SENTRI TECH ${ }^{\mathrm{TM}}$.

The underground baits made of only poplar wood of different shapes put in green plastic boxes with holes to permit to the termites to enter inside and start to feed them. This for understanding the flow from the nest.

The commercial names of these wooden baits were SENTRI SOL (SSL), constituted by a plastic cylinder with four series of fifteen holes around and a conic bottom. The SENTRI TEST19 (ST 19) was a plastic hexagonal box with a cover on the top and an open bottom. Further, untreated were inserted the baits inside poplar wood blocks.

Furthermore, palm (Coco nucifera), Corsican pine (Pinus nigra subsp. laricio Maire) beech (Fagus sylvatica L.) wood blocks, attacked by termites, found in the sawmill of the Monastery, put inside the hexagonal plastic SENTRI boxes and also utilized as baits. The baits were always wet before of being put underground.

Above-ground bait stations (SENTRI BOX, SB) were reclosable plastic stations attached directly over infested wood or foraging tubes so that termites could freely enter inside the boxes through a pre-cut hole in its bottom. These SB stations are totally closed by means of secured child-resistant covers, to ensure the termites an enclosed, dark and stable chamber. During the first monitoring stage, baits SB could contained a matrix of laminated texture cellulose (LTC5) not treated with IGR or impregnated with hexaflumuron (HES). The above-ground stations allowed to investigate termite presence in structures and to contact termite colonies creating well-known foraging points. The bait matrix was immediately available for termites foraging in those areas. In some cases, to 
evaluate the eating preference of termites the LTC 5 was substituted by filter paper without any active ingredient.

23 SSL and 12 ST 19 baits and without any IRG substance were placed around the external perimeter of the church; 24 palm (Coco nucifera) wood blocks inside plastic box was also utilized.

The distribution of monitoring station is shown in Figure 1.

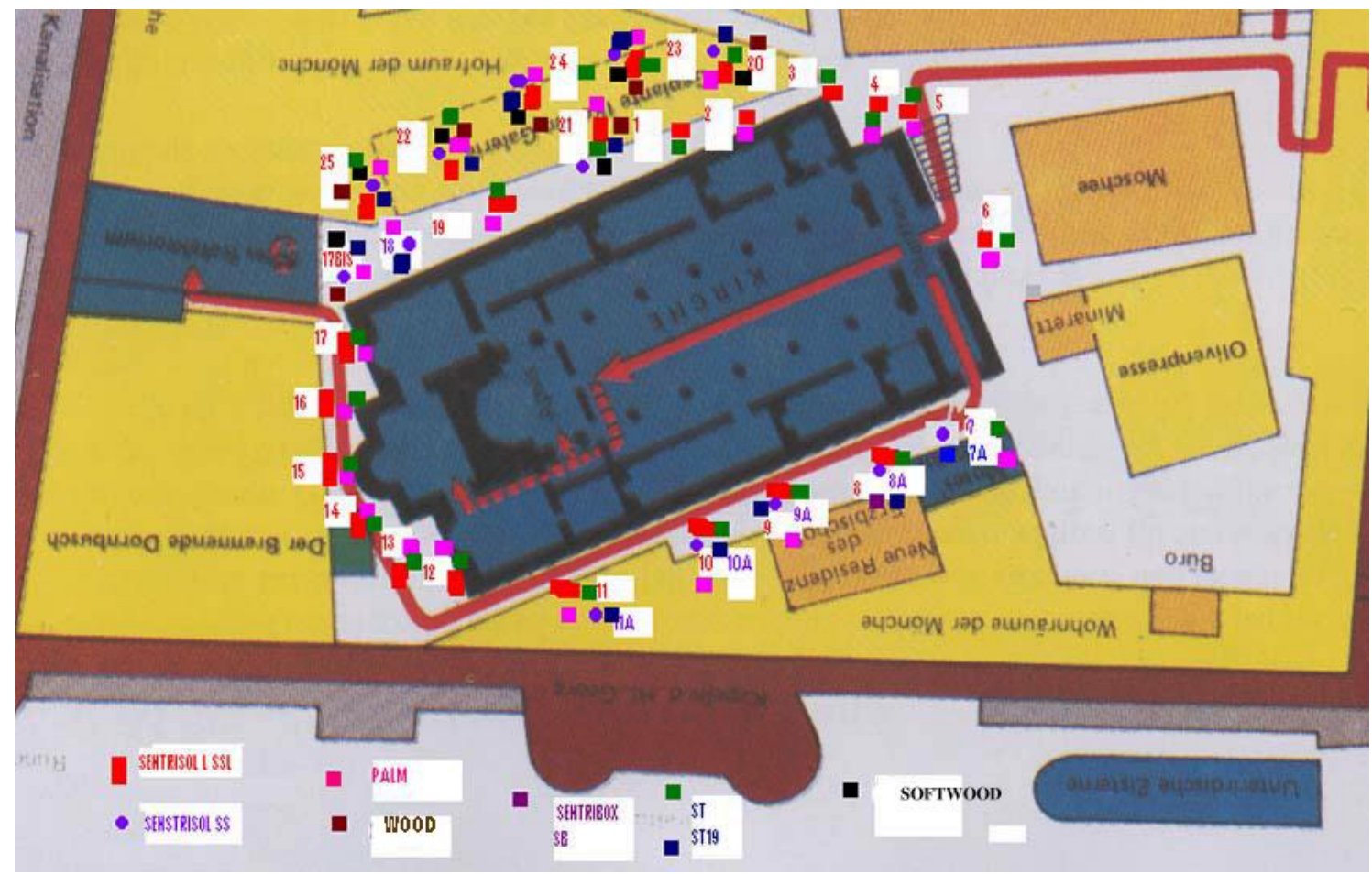

Figure 1. Distribution of different types monitoring stations around the St Catherine church. In the bottom of figure are reported the legend of stations The black and brown square represents the non-identified wood species.

In some position both station SS and bait ST 19 were utilized.

Inside the church were placed $16 \mathrm{SB}$ baits with cellulose impregnated with active ingredient Hexaflumuron $5 \% \mathrm{w} / \mathrm{w}, 5$ ST 19 under the floor, and 3 SB with only filter paper as represented in Figure 2. Further, in the ground some SS stations were positioned. 


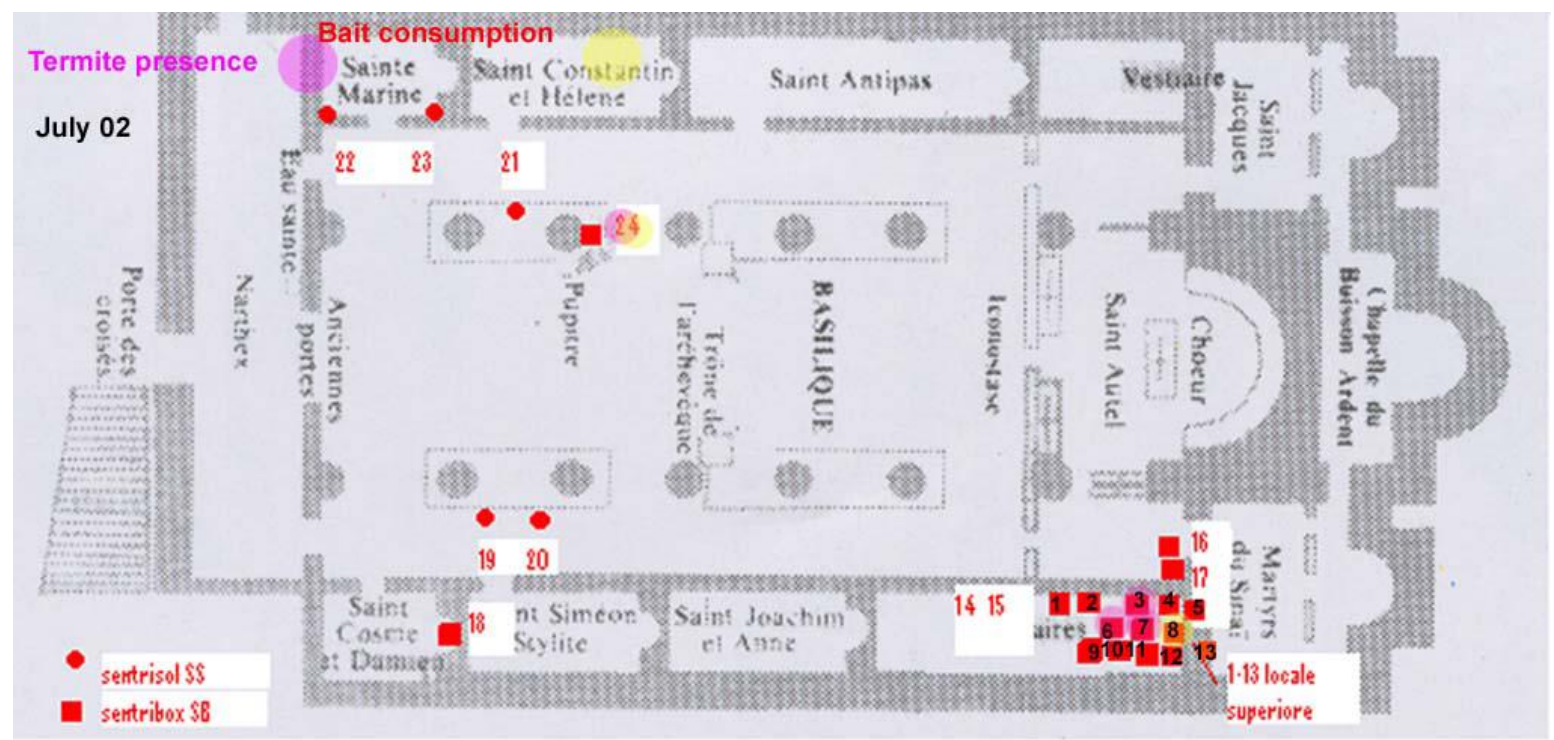

Figure 2. The distribution of SENTRI boxes and SENTRI SOL into the ground under the floor inside the church.

\section{Results}

During the inspection carried out in June 2002, most of the sites individuated in the St Catherine Monastery the year before, were observed in the same condition without any increase of the infestation. Further, during the inspection, two new sites with decay, tunneling and living termites were revealed inside the church.

The SENTRI TECH evaluations were carried out, one time for month, between July 2002 and June 2003 as reported in Figures 3 e 4.

The termites inside and around the St Catherine church stopped its activity into the stations since January 2003, but if inside no activity restarted in the successive spring and summer, in the external stations the trend was more fluctuant and started again in the spring until the number of the second evaluation, in the third inspection in August 2002 with even an increasing in the monthly consumption. 


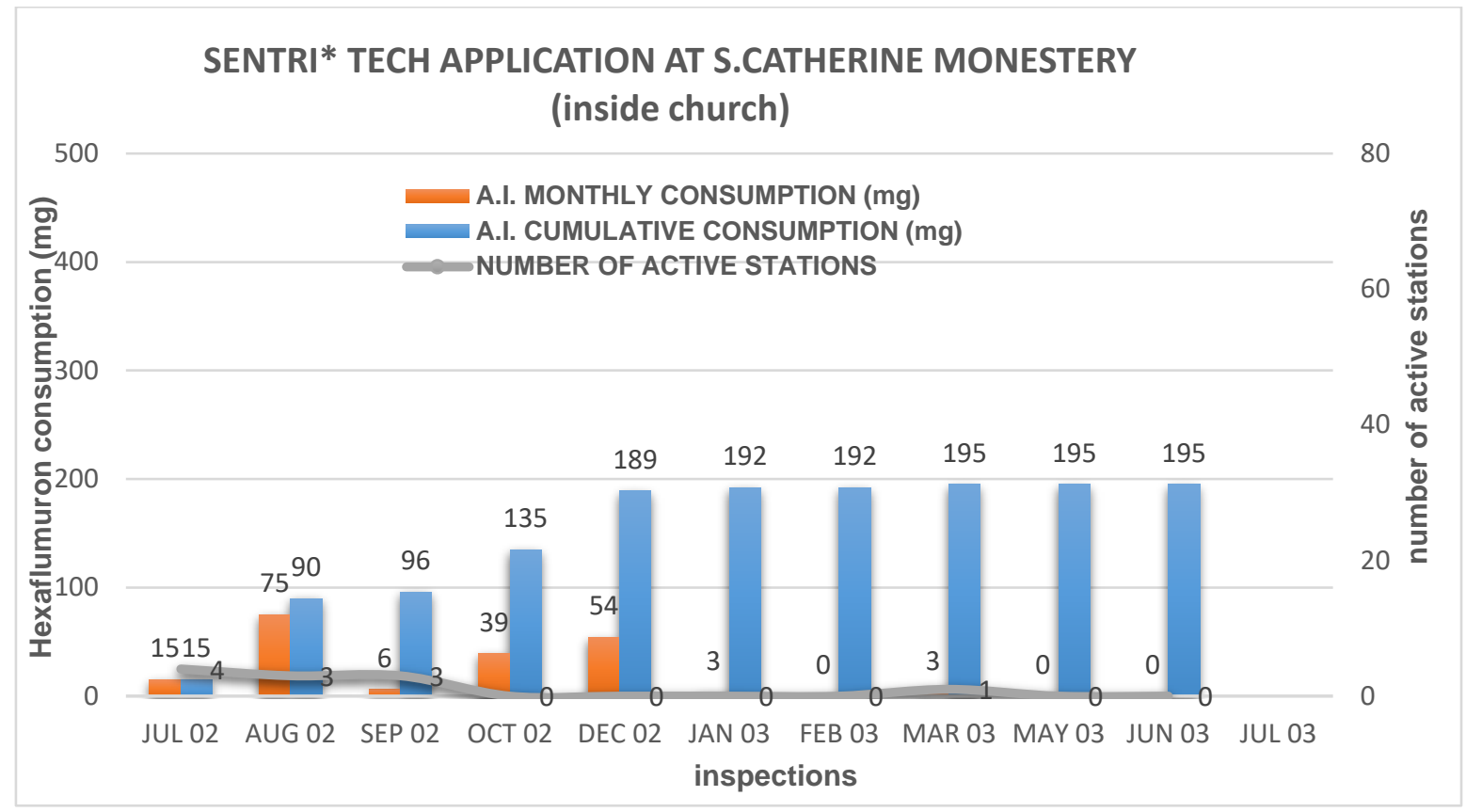

Figure 3. The evaluation of Hexaflumuron consumption from July 2002 to July 2003 inside the Church of St Catherine.

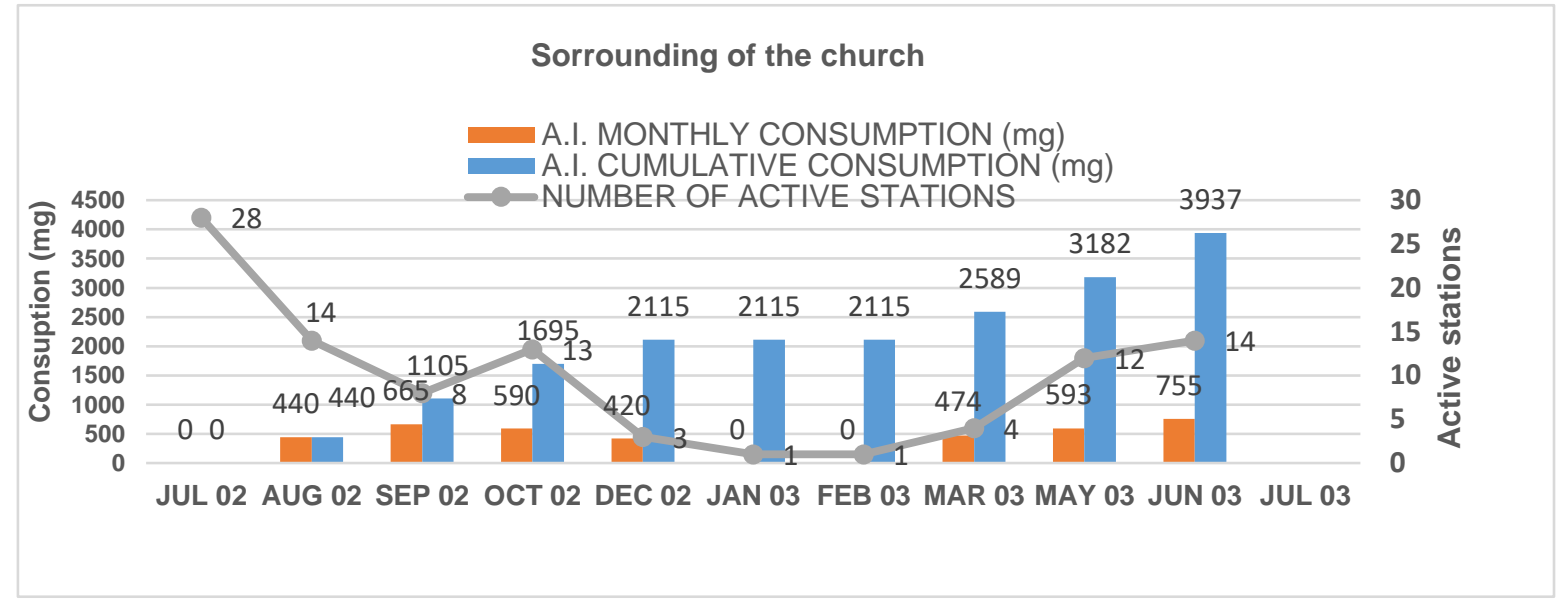

Figure 4. The evaluation of Hexaflumuron consumption from July 2002 to July 2003 in the surrounding the Church of St Catherine.

\section{Discussion}

The termite attack seemed to be highly destructive and probably it has been well rooted for many years. Only from 2001, at the time of first inspection, damages have been clearly detected and diagnosed; infestation could be due to a well rooted presence of this termite species in the area.

The Church is located on the bottom part of the Monastery building complex and of the narrow valley were St. Catherine rises, the soil under the Basilica is constantly moistened due to underground waters and dwell. Other parts of the Monastery, even at top levels (surrounding walls), were seriously hit in the past: clear infestation traces (mud tubes, empty poles and beams, carob trees in the garden) can be easily detected.

As already published research based both on morphological comparison and mitochondrial DNA analysis reported [6] that the termites found in the Monastery belonged to two Higher Termites 
species (Termitidae) Amitermes vilis and Microcerotermes eugnathus. These two species are adapted to semi-arid or arid regions where they can be found where some water was available, such as in the bottom of valleys, in oases, vegetated patches, or irrigated areas.

During the inspection was reported [6] some peculiarities as slight photonegative behavior; high sensitivity to relative humidity (the desert air is very dry: $25 \%$ R.H.); for water supply they could tunnel deeply in the ground (but the water table under the Basilica seem to be very closed to the surface); It was observed preparation of mud tubes and sealing activity to prevent humidity loss and atmosphere control, instead in lab condition the termites collected showed low digging and building capability, no mould above ground; food preference for palm wood (Coco nucifera) and almond wood (Prunus amygdalus), but inside building they were able to use different food sources simultaneously; these species, like other subterranean termites, nesting sites and feeding sites are well separated and connected by a system of tunnels; so far, it seemed the colony forms an illdefined nest system underground (under stumps or partly dead trees) or in fallen woods near soil, including a series of chambers and galleries. They had large colonies or open nests: termites collected from 2 stations far $30 \mathrm{~m}$. each other and put together for testing in arena (10 workers and 1 soldier vs. 10 workers and 1 soldier; 3 replicates) displayed social behavior patterns like touch and vibration, licking and trophallaxis, same as observed between termites from the same station; in other species (genera Reticulitermes) open nest colonies may be numerous up to millions of individuals and with a wide foraging area; It was observed also intraspecific highly aggressive behavior between 2 different colonies put together for testing in arena ( 10 workers and 1 soldier vs. 10 workers and 1 soldier; 3 replicates).

For that reason it was not easy to explain why after 9 months Hexaflumuron baiting in the Monastery area (termite control experimental project) termites disappeared from the internal area of the church, but they continued to be found in underground stations outside baits.

This fact could be due to frequentation and consumption of bait stations are continuous and with no abandonment; termites died with uric acid deposits, deformed abdomens, less activity, loss of caste varieties. Nevertheless, humidity of the Monastery buildings attracts termites from all the surrounding and their density in this point increases. The treatment was supposed to last for a long time in order to allow the extinction of all the termites that approached the monastery. Obviously this hypothesis is possible only from a theoretical point of view it was not possible to pursue it. Another hypothesis could due to the utilization of sub-lethal dose of hexaflumuron on this termites specie. In the latter case, even this was only possible through an experimental approach, it was difficult to reach because Sentitech ${ }^{\mathrm{TM}}$ had no economic interest in investing in these termites species.

\section{Conclusions}

The application of the European registered bait system to an infestation of Higher termites in the Holy Monastery of St Catherine gave the following results:

The infestation inside the church stopped after 6 month and after the consumption of $192 \mathrm{mg}$ of hexaflumuron. Nevertheless in the surrounding of the church the infestation seemed to be blocked after five months and $2115 \mathrm{mg}$ of hexaflumuron consumption, it started again and increased from sixth month to eight month.

An attempted explanation of this surprising fact was due to the humidity of the Monastery that could be act as attractive associated to the use of a sub-lethal dose of hexaflumuron.

Funding: This research was funded by Dow AgroSciences. 
Acknowledgments: The Authors wants to thanks dott.sa Valeria Zaffagnini, Dow Agrosciences and Dott.sa Anna Gambetta, CNR IRL (former CNR IVALSA former CNR IBE) for making possible this experimentation. Finally, we want to express our gratitude to the Archbishop Mons. Damianos, to the Saint Council and all Fathers of the Saint Catherine Holy Monastery for their valuable assistance and contribution, towards the accomplishment of this important project.

Conflicts of Interest: The authors declare no conflict of interest.

\section{References}

1. The St. Catherine area, South Sinaï, Egypt, as a mixed world cultural and natural heritage site The World Heritage Committee (2002).

2. Gambetta, A; Zaffagnini, V.; De Capua., E.. Use of Hexaflumuron baits against subterranean termites for protection of historical and artistic structures: experiment carried out in selected test areas at the church of Santa Maria della Sanità in Naples. Journal of Cultural Heritage, 1, 3, 207-216 (2000) DOI: 10.1016/S12962074(00)01080-3

3. Su, N.-Y; Scheffrahn, R.H.. Laboratory evaluation of two chitin synthesis inhibitors, Hexaflumuron and diflubenzuron, as bait toxicants against Formosan and eastern subterranean termites (Isoptera: Rhinotermitidae), J. Econ. Entomol. 86 , 1453-1457 (1993).

4. N.-Y. Su.. Field evaluation of a Hexaflumuron bait for population suppression of subterranean termites (Isoptera: Rhinotermitidae), J. Econ. Entomol. 87, 389-397 (1994).

5. Su, N.-Y; Thoms, E.M.; Ban P.M; Scheffrahn R.H.. A monitoring baiting station to detect and eliminate foraging populations of subterranean termites (Isoptera : Rhinotermitidae) near structures, J. Econ. Entomol. 88, 932-936 (1995).

6. Ghesini, S.; Marini, M.. Termites of the Monastery of Saint Catherine Sinai, Egypt. Bulletin of Insectology 70, (1), 1-8, 2017 ISSN 1721-8861 (2017).

7. Harris W.V.; Termites of the Palearctic region in Biology of Termites (ed. by K. Krishna and F. M. Weesner), 295-313. Academic Press, New York (1970). 